OAI-PMH: http://www.indteca.com/ojs/index.php/Revista Scientific/oai

Artículo Original / Original Article

\title{
Relación entre los Trastornos de la Conducta Alimentaria (TCA) y los ideales de belleza femenina
}

Autora: Claudia Gabriela Terán Ledesma Universidad Internacional SEK, UISEK claudia.teran@uisek.edu.ec Quito, Ecuador https://orcid.org/0000-0001-7802-2830

\section{Resumen}

Una de las aproximaciones más comunes de los Trastornos de la Conducta Alimentaria (TCA) consiste en señalar la incidencia de las imágenes publicitarias, que imponen una suerte de culto a la delgadez extrema, en los trastornos de la imagen corporal. La complejidad de la sintomatología que caracteriza a los TCA nos lleva a interrogar este presupuesto, en el que finalmente se excluye la palabra de las propias mujeres y se privilegia el análisis de la problemática social que, sin carecer de importancia, resulta insuficiente para explicar las manifestaciones clínicas de la anorexia y la bulimia nerviosas. El objetivo de la presente investigación es especificar las formas en las que los discursos sociales ligados a los ideales de belleza dan cuenta de los TCA. A través de una investigación de campo, utilizando un enfoque cualitativo y con la implementación de un diseño exploratorio descriptivo y de temporalidad transversal, se entrevistó a un grupo de mujeres que tienen un diagnóstico de TCA y a un grupo de mujeres que no posee tal diagnóstico (grupo control), se demostrará que el rechazo radical del cuerpo, de lo femenino y sus manifestaciones se sitúa como la principal problemática concernida en este tipo de trastornos.

Palabras clave: trastorno; publicidad; feminidad.

Código de clasificación internacional: 6101.01 - Desórdenes del comportamiento.

\footnotetext{
Cómo citar este artículo:

Terán, C. (2021). Relación entre los Trastornos de la Conducta Alimentaria (TCA) y los ideales de belleza femenina. Revista Scientific, 6(22), 38-55, e-ISSN: 2542-2987. Recuperado de: https://doi.org/10.29394/Scientific.issn.2542-2987.2021.6.22.2.38-55
}

Fecha de Recepción: 13-01-2021
Fecha de Aceptación:

07-06-2021
Fecha de Publicación: 05-11-2021 
OAl-PMH: http://www.indteca.com/ojs/index.php/Revista Scientific/oai

Artículo Original / Original Article

\title{
Relationship between Eating Disorders (ED) and feminine beauty ideals
}

\begin{abstract}
One of the most common approaches to Eating Disorders (Eating Disorders) consists in pointing out the incidence of advertising images, which impose a kind of cult of extreme thinness, in body image disorders. The complexity of the symptomatology that characterizes eating disorders leads us to question this assumption, in which the word of women themselves is finally excluded and the analysis of social problems is privileged, which, without being unimportant, is insufficient to explain the Clinical manifestations of anorexia and bulimia nervosa. The objective of this research is to specify the ways in which social discourses linked to beauty ideals account for ED. Through a field investigation, using a qualitative approach and with the implementation of a descriptive and cross-temporal exploratory design, a group of women who have an eating disorder diagnosis and a group of women who do not have such a diagnosis were interviewed (control group), it will be demonstrated that the radical rejection of the body, the feminine and its manifestations is the main problem concerned in this type of disorders.
\end{abstract}

Keywords: disorder; advertising; femininity. International classification code: 6101.01 - Behaviour disorders.

\section{How to cite this article:}

Terán, C. (2021). Relationship between Eating Disorders (ED) and feminine beauty ideals. Revista Scientific, 6(22), 38-55, e-ISSN: 2542-2987. Recovered from: https://doi.org/10.29394/Scientific.issn.2542-2987.2021.6.22.2.38-55

Date Received: 13-01-2021
Date Acceptance: 07-06-2021
Date Publication: 05-11-2021 


\section{Introducción}

Para la mitología griega y romana, los cánones de belleza cumplían una función, al establecer una distinción clara entre lo masculino y lo femenino. Señalando a García-Ochoa (2010): el culto al cuerpo del hombre joven difiere así de la posición que se otorga al cuerpo femenino. Para las mujeres, el cuerpo da cuenta principalmente de una posición social: las esclavas son delgadas y frágiles, mientras que las mujeres que detentan poder o autoridad se imponen con un cuerpo portentoso.

Esta clasificación imaginaria de la sociedad se establece de manera durable hasta la época del renacimiento, en donde los ideales de belleza femenina apuntan a distinguir a los miembros de la aristocracia. Las mujeres de otras clases sociales no tenían, bajo esta premisa, derecho a la mirada de los otros y, por tanto, los principios estéticos establecidos no las concernían. La belleza femenina llega a ser entonces signo de estatus, al tiempo que aseguraba una forma de pertenencia a la sociedad.

Contrariamente, Moreira (2015): a lo que sucedía en épocas pasadas, en el siglo XXI la diferencia entre lo masculino y lo femenino es cada vez menos clara, así como la diferencia entre clases sociales; transformada por la ideología de mercado. En medio de la desorientación del sujeto posmoderno como ser sexuado y como parte de la sociedad, los modelos preconcebidos de belleza representan una definición preconfeccionada del propio ser, aun cuando el recurso a esta "solución" se paga con el precio de la patología.

Mencionando a Rutsztein, Murawski, Elizathe y Scappatura (2010): la elevada prevalencia de los Trastornos de la Conducta Alimentaria (TCA) en el contexto iberoamericano, en particular de la anorexia y bulimia nerviosas, ha alcanzado una especial relevancia en las últimas tres décadas, al punto que ha llegado a considerarse un problema de salud pública que debe atenderse de manera global, tanto desde la perspectiva de la intervención como de la prevención. 
El factor de riesgo más frecuentemente documentado en los TCA es la insatisfacción acerca de la propia imagen corporal, observándose además que la sintomatología se presenta cada vez a edades más tempranas. Varios estudios como el de Lameiras, Calado, Rodríguez y Fernández (2003): evidencian que un elevado porcentaje de niñas españolas cuyas edades fluctúan entre los 7 y 12 años manifiestan que desean estar más delgadas. Este porcentaje se incrementa en la adolescencia hasta en un $80 \%$.

En conformidad con Peláez, Raich y Labrador (2010): en España, la irrupción de los TCA a partir de la década de los ochenta se ha extendido masivamente a todos los sectores sociales y presenta mayores índices de prevalencia entre la población femenina. No obstante, las manifestaciones de los TCA en la actualidad se sostienen de aspectos cada vez más difíciles de situar.

De hecho, los aspectos culturales y sociales forman parte de la configuración formal de los TCA. Sin embargo, varios estudios presentan dichos aspectos como el principal factor involucrado en esta problemática y llegan a afirmar según Maganto, Del Río y Roiz (2000), citados por Maganto y Cruz (2000): que se trata de un "trastorno natural o étnico [...]" (pág. 46); "inexistentes en el mundo no occidental o en países subdesarrollados [...]" (pág. 47). Consideramos que se trata de una afirmación que merece ser cuestionada.

Por otra parte, una de las aproximaciones más comunes de los TCA consiste en asociar la incidencia de los discursos sociales que proponen una suerte de culto a la delgadez extrema, con los trastornos de la imagen corporal. El imaginario social vehicula, en efecto, una representación de la mujer que se encuentra prácticamente desligada de su dimensión humana, reduciéndola al estatuto de pura imagen.

No obstante, la complejidad de la sintomatología que caracteriza a los TCA nos lleva a interrogar este presupuesto, en el que finalmente se excluye 
la palabra de las propias mujeres y se privilegia el análisis de la problemática social que, sin carecer de importancia, resulta insuficiente para explicar las manifestaciones clínicas de la anorexia y la bulimia nerviosas.

Para Plaza (2010): es innegable que los medios de comunicación ejercen una gran influencia en la adolescencia y contribuyen significativamente a adoptar y mantener las normas que impone la cultura de la delgadez. Pero ¿existe una incidencia significativa de las campañas mediáticas en la propia percepción del cuerpo en el ámbito de los TCA, o se trata más bien de una problemática que involucra la posición subjetiva del sujeto en otros aspectos?

La presente investigación se propone especificar las formas en las que el discurso social ligado a los ideales de belleza preponderantes en la sociedad occidental da cuenta de los TCA. En caso de que se demuestre un rol importante de la influencia mediática en este tipo de trastornos, nuestra investigación podría contribuir a la profundización de futuros estudios que se soporten en esta hipótesis. Por el contrario, si esta relación se muestra poco significativa, podríamos sostener la importancia de privilegiar el análisis de la psicopatología de los TCA desde un enfoque de caso por caso.

Sostenemos, de hecho, que los TCA presuponen una posición subjetiva particular con relación a lo femenino. De igual manera, constatamos que la construcción de la identidad y de la percepción del propio cuerpo se sitúan más allá de la imagen ideal vehiculizada por el contexto social. Los TCA parecerían evidenciar, por una parte, la entera sumisión del sujeto a los dictámenes sociales. Al acercarnos a la patología desde la perspectiva de cada caso, identificamos más bien el fracaso, en acto, de los ideales estéticos, puesto que no alcanzan a dar cuenta de la identidad del sujeto en trastornos como la anorexia y la bulimia nerviosas.

De este modo, Vaquero-Cristóbal, Alacid, Muyor y López-Miñarro (2013): manifiestan que la complejidad en juego en los TCA parece no reducirse a la cuestión de la propia imagen, aun cuando las perturbaciones de 
lo imaginario aparecen en primer plano. Varios estudios avanzan que aquello

que plantea como problema no es tanto la imagen del cuerpo como tal, sino el modo en que el propio cuerpo se manifiesta al sujeto.

El sujeto anoréxico se encuentra escrutado por una mirada exterior; una mirada inhumana, cuando no persecutoria. En conformidad con Murguía (2013): según varios estudios, el principal objetivo de la mayoría de las dietas de carácter estético es obtener un cuerpo que pueda ser exhibido, ante el cual el otro pueda dirigir una mirada amable. Para ello, se han transgredido ciertos límites, cuyo resultado son las patologías de la conducta alimentaria.

En cuanto a la publicidad "pro-esbeltez" en los medios de comunicación, se espera un mayor alcance entre las mujeres. Al respecto, Del-Río-Pérez, y Medina-Aguerrebere (2014): realizaron un análisis de publicidad española a finales de los años 1980 y observaron que uno de cada cuatro anuncios invitaba directa o indirectamente a perder peso. En ellos se promovía la idea de que el cuerpo puede ser modificado hasta alcanzar un ideal de "perfección" que, al mismo tiempo, excedía los límites trazados por lo cultura, la construcción de la identidad y los valores comunitarios, en función de atributos físicos que se pretendían además universales y válidos para todas las mujeres.

Las mujeres afectadas por los TCA sitúan los aspectos patógenos de esta condición alrededor de aspectos más estructurales, en particular el rechazo del propio cuerpo, de la propia feminidad y de la sexualidad. Observaremos además el rol que juegan los criterios sociales de belleza y feminidad en las manifestaciones clínicas de estos trastornos, en tanto que instancias de control externas al sujeto.

Otro aspecto clínico fundamental observado en los TCA es la afectación de los vínculos sociales. Las pacientes consideran que su cuerpo no será aceptado por los otros ni que su presencia o compañía será considera deseable para los demás. Por su parte, Raich (2004): define esta problemática en términos de "ansiedad interpersonal" (pág. 20); y explica que el individuo 
se aislará gradualmente debido a la angustia generada por el contacto con otros. Se observa además que esta dificultad concierne a todas las esferas de la vida social y alcanza el ámbito laboral, familiar y de pareja. Para Pereña (2007): la vida sexual se reduce al mínimo, cuando no es rechazada por completo.

La dominación de un cuerpo que aparece al sujeto como extranjero a sí mismo parecería estar implicado en los TCA. Se ha documentado ampliamente acerca de los factores de "disciplina y autocontrol" evidenciados en las patologías de la alimentación, acorde con Morales, Ramírez, Ureña, Sevilla, Umaña y Chavez (2002): es en donde el individuo tiene la ilusión de autonomía y de un absoluto control sobre su cuerpo.

A partir de estas reflexiones, nos planteamos la pregunta acerca de cómo se relacionan las mujeres con su cuerpo en la actualidad; relación que fluctúa entre las prácticas de cuidado y bienestar, hacia un forzamiento en el que prevalece el rechazo de la imagen que el propio cuerpo les reenvía. La problemática parece entonces concernir el estatuto mismo del cuerpo y del ser que lo habita, mismo que se encuentra inevitablemente atravesado por la cultura y el discurso social.

La presente investigación se plantea como objetivo analizar la especificidad de estos trastornos, teniendo en cuenta la relación existente entre el desarrollo de trastornos de la conducta alimentaria y los discursos hegemónicos que se presentan en función de un contexto sociocultural dado.

\section{Metodología}

La presente investigación plantea un enfoque cualitativo, en el que se empleará un diseño exploratorio descriptivo y una temporalidad transversal. Se procedió a la recolección y el análisis de datos para su estudio mediante una entrevista semiestructurada a mujeres entre 18 y 45 años.

Durante la primera parte de la entrevista se documentó la respuesta de 
cada una de las participantes a un cuestionario de nueve preguntas abiertas acerca de la percepción de la propia imagen corporal y su relación con los ideales sociales de belleza. Durante la segunda parte de la entrevista se expusieron a 4 fotografías publicitarias a cada participante, seleccionadas por su contenido, en tanto que éste puede hacer alusión a los ideales de belleza establecidos por la sociedad y vehiculizados por el marketing y la publicidad.

Posteriormente, se procedió a un análisis interpretativo de las respuestas obtenidas mediante el método de teoría fundamentada. Este último permite la construcción de categorías teóricas a partir del análisis de datos obtenidos, de manera que se pueda establecer una relación entre éstas.

La muestra está conformada por 10 participantes. Cinco de ellas tienen un diagnóstico de TCA y se encuentran recibiendo tratamiento en un Hospital del día de la Unidad de Psiquiatría especializada en Atención de los Trastornos de la Dieta Alimentaria. Las otras cinco participantes pertenecen al Grupo control y no tienen diagnóstico referente a esta problemática.

El muestreo fue intencionado con criterios de inclusión y exclusión. Los criterios de inclusión para el primer grupo fueron: cursar o haber cursado estudios superiores, tener un diagnóstico hospitalario de TCA, encontrarse bajo tratamiento en el Hospital del día y no presentar otros diagnósticos. Los criterios de inclusión para el Grupo control fueron: cursar o haber cursado estudios superiores, no tener diagnóstico relacionado a problemáticas de los hábitos alimentarios u otros trastornos y presentar un Índice de Masa Corporal (IMC) normal.

\section{Resultados}

Los temas y categorías que resultaron de la codificación de ambos grupos son sumamente diferentes. Se puede apreciar una discrepancia significativa en la percepción de la imagen corporal del grupo TCA con el grupo control. 
Las categorías del grupo TCA describen una forma ambivalente e insatisfactoria de percibir la propia imagen, mientras que en el grupo control se aprecia una aceptación y admiración del propio cuerpo y sus particularidades, a pesar de que dichas particularidades no correspondan a las imágenes propuestas por la publicidad.

Tabla 1. Percepción de la propia imagen corporal (Grupo TCA).

\begin{tabular}{|c|c|c|}
\hline Temas & Categorías & Puntuación \\
\hline \multicolumn{3}{|c|}{ (Número de referencias textuales) } \\
\hline Carcasa & Cuerpo físico & 14 \\
\hline \multicolumn{3}{|l|}{ Órganos } \\
\hline \multicolumn{3}{|l|}{ Medio para lograr un fin } \\
\hline Vergüenza & Rechazo & 48 \\
\hline \multicolumn{3}{|l|}{ Miedo } \\
\hline \multicolumn{3}{|l|}{ Amorfo } \\
\hline \multicolumn{3}{|l|}{ Asco } \\
\hline \multicolumn{3}{|l|}{ Rabia } \\
\hline \multicolumn{3}{|l|}{ Sin belleza } \\
\hline No hay belleza & Desconexión & 12 \\
\hline \multicolumn{3}{|l|}{ No es mi cuerpo } \\
\hline \multicolumn{3}{|l|}{ Belleza perdida } \\
\hline Cuerpo enfermo & Enfermedad & 11 \\
\hline \multicolumn{3}{|l|}{ Delgado } \\
\hline \multicolumn{3}{|l|}{ Mal } \\
\hline Olvidar el cuerpo & Castigo & 13 \\
\hline \multicolumn{3}{|l|}{ Castigarse } \\
\hline \multicolumn{3}{|l|}{ Maltratarse } \\
\hline No me ven como yo me veo & Distorsión & 13 \\
\hline Otros deciden qué es bello & Locus de control externo & 44 \\
\hline Bello más allá de lo físico & Belleza interna & 15 \\
\hline
\end{tabular}

Fuente: La Autora (2020).

En la tabla 1, la categoría con mayor puntuación en el grupo TCA fue la 
que se identificó como "Rechazo". En ella, se hacen referencias sistemáticas a la crítica y a la descalificación del propio cuerpo.

En el grupo TCA no existe ninguna temática que refleje un reconocimiento de los rasgos que las hacen singulares. Sorprende la manera en que las participantes no reconocen en ellas mismas ninguna característica corporal o personal que las vuelva amables.

El discurso de las participantes de este grupo se apega enteramente a la insatisfacción corporal y existencial. Se observa incluso que dicha insatisfacción no se encuentra determinada por las imágenes publicitarias. Las participantes del grupo TCA parecerían afirmar: que las modelos de la publicidad son muy hermosas. Pero aún si lograra verme así, no estaría satisfecha conmigo misma.

Tabla 2. Percepción de la propia imagen corporal (Grupo Control).

\begin{tabular}{|c|c|c|}
\hline Temas & Categorías & Puntuación \\
\hline \multicolumn{3}{|c|}{ (Número de referencias textuales) } \\
\hline Soy yo & Identidad & 19 \\
\hline \multicolumn{3}{|l|}{ Parte de mi } \\
\hline \multicolumn{3}{|l|}{ Identidad } \\
\hline Físico & Lo físico & 7 \\
\hline \multicolumn{3}{|l|}{ Orgánico } \\
\hline \multicolumn{3}{|l|}{ Aspecto } \\
\hline \multicolumn{3}{|l|}{ Superficial } \\
\hline Admiración & Me gusta mi cuerpo & 61 \\
\hline \multicolumn{3}{|l|}{ Amor } \\
\hline \multicolumn{3}{|l|}{ Positivo } \\
\hline \multicolumn{3}{|l|}{ Libre } \\
\hline \multicolumn{3}{|l|}{ Feliz } \\
\hline Fuerte & Presencia & 19 \\
\hline \multicolumn{3}{|l|}{ Atlético } \\
\hline \multicolumn{3}{|l|}{ Expresivo } \\
\hline \multicolumn{3}{|l|}{ Ocupa un espacio } \\
\hline Rabia & Imperfección & 20 \\
\hline
\end{tabular}


Instituto Internacional de Investigación y Desarrollo Tecnológico Educativo INDTEC, C.A.

DOI: https://doi.org/10.29394/Scientific.issn.2542-2987.2021.6.22.2.38-55

OAI-PMH: http://www.indteca.com/ojs/index.php/Revista Scientific/oai

\section{Artículo Original / Original Article}

\begin{tabular}{|c|c|c|}
\hline Ambivalencia & & \\
\hline Imperfección & & \\
\hline Único & Belleza: Cuerpo único & 34 \\
\hline Diferente & & \\
\hline Belleza propia & & \\
\hline Mi cuerpo & & \\
\hline Mi belleza & & \\
\hline Patrón & Patrones de belleza & 34 \\
\hline Sociedad & & \\
\hline Otros deciden & & \\
\hline Economía de $n$ & & \\
\hline Rabia & & \\
\hline Belleza & Belleza interna & 15 \\
\hline Fuerza & & \\
\hline Aceptación & & \\
\hline Expresividad & & \\
\hline Diferencia & & \\
\hline Belleza interna & & \\
\hline
\end{tabular}

Fuente: La Autora (2020).

Por su parte, para la tabla 2, la categoría con mayor puntuación en el grupo control fue la que se denominó "Me gusta mi cuerpo", puesto que contiene temas que denotan aceptación y una descripción positiva del propio cuerpo.

Señalaremos que ambos grupos crearon categorías asociadas a la percepción negativa del cuerpo; estas categorías son más numerosas y significativas en el grupo con TCA. En el grupo control apareció la categoría "Imperfección”, que abarca todas las afirmaciones que apuntan a señalar las fallas e imperfecciones del propio cuerpo, con las que las participantes no se encuentran enteramente satisfechas.

No obstante, en el grupo control estas percepciones se encuentran enteramente contrabalanceadas con aquellas que dieron lugar a la categoría "Belleza/Cuerpo único". Ésta explica que, a pesar de tener imperfecciones, el 
cuerpo tiene una belleza propia y única. Se otorga un valor a lo particular de cada cuerpo. Se acentúan rasgos únicos que se encuentran ligados a características individuales que van más allá de la imagen, aun cuando éstos no correspondan a los cánones establecidos por la publicidad.

Del mismo modo, ambos grupos presentan amplias categorías que relacionan la percepción de lo bello con patrones sociales; es decir, que esta percepción se impone a través de criterios externos a las propias mujeres. En el grupo TCA es notable cómo la belleza se percibe en todos los casos como un factor externo, algo que no forma parte de su ser o de su identidad. Lo bello no es admitido como una categoría que concierne otra dimensión que la del cuerpo. Las participantes parecerían adherir a un concepto de belleza absolutamente reduccionista y que, difiere de la lógica presentada por la publicidad que identifica de manera simplista delgadez y belleza.

En el grupo control, por el contrario, la belleza está incluida en la descripción que las participantes hacen de sí mismas. Estas descripciones se extienden a otros ámbitos, y van más allá de la imagen corporal, cuya percepción aparece fuertemente conectada con aspectos como la personalidad, el carácter, los valores o la sociabilidad.

Durante la segunda parte de la entrevista, a la que se denominó "Sobre el material fotográfico", las categorías que aparecen son relativamente similares en ambos grupos. Se observa una marcada discrepancia entre los dos grupos en cuanto a la respuesta que suscita cada fotografía.

Tabla 3. Sobre material fotográfico (Grupo TCA).

\begin{tabular}{|l|l|l|}
\hline \multicolumn{2}{|c|}{ Temas } & \multicolumn{2}{c|}{ Categorías } & Puntuación \\
\hline \multicolumn{2}{|c|}{ (Número de referencias textuales) } \\
\hline Desagrado & Respuesta negativa & 19 \\
\hline Incomodidad & & \\
\hline Vergüenza & & \\
\hline Angustia & & \\
\hline Rabia & & \\
\hline Asco & & \\
\hline Falsedad & & \\
\hline
\end{tabular}


Instituto Internacional de Investigación y Desarrollo Tecnológico Educativo INDTEC, C.A.

DOI: https://doi.org/10.29394/Scientific.issn.2542-2987.2021.6.22.2.38-55

OAI-PMH: http://www.indteca.com/ojs/index.php/Revista Scientific/oai

Artículo Original / Original Article

\begin{tabular}{|c|c|c|}
\hline Ser objeto & & \\
\hline Comparación imposible & No identificación & 30 \\
\hline No hay diferencia & & \\
\hline No sé cómo me veo yo & & \\
\hline No soy como ella & & \\
\hline No me veo ahí & & \\
\hline Buena actitud & Respuesta positiva & 20 \\
\hline Alegría & & \\
\hline Positivo & & \\
\hline Seguridad & & \\
\hline Igualdad & & \\
\hline Valentía & Ambivalencia & 26 \\
\hline Vergüenza & & \\
\hline Admiración & & \\
\hline Disgusto & & \\
\hline Confusión & & \\
\hline Fragilidad & Feminidad & 6 \\
\hline Feminidad & & \\
\hline Oscuridad & Enigma & 8 \\
\hline Seriedad & & \\
\hline Opacidad & & \\
\hline
\end{tabular}

Fuente: La Autora (2020).

Para la tabla 3, el grupo TCA no muestra ninguna apreciación o admiración por la fotografía en su conjunto ni por una parte de ésta. No logran identificarse a sí mismas en ninguna de las situaciones recreadas. Parecería que un sentimiento de "no-existencia" prevalece en cada una de las participantes.

Tabla 4. Sobre material fotográfico (Grupo Control).

\begin{tabular}{|l|l|c|}
\hline \multicolumn{1}{|c|}{ Temas } & \multicolumn{1}{c|}{ Categorías } & Puntuación \\
\hline \multicolumn{2}{|c|}{ (Número de referencias textuales) } \\
\hline Rabia & Indignación & 15 \\
\hline Confusión & & \\
\hline Indignación & & \\
\hline \multicolumn{2}{|l|}{} \\
\hline Falsa & Yo soy más real & 13 \\
\hline Retocada & & \\
\hline Yo soy más real & & \\
\hline
\end{tabular}


Instituto Internacional de Investigación y Desarrollo Tecnológico Educativo INDTEC, C.A.

DOI: https://doi.org/10.29394/Scientific.issn.2542-2987.2021.6.22.2.38-55

OAI-PMH: http://www.indteca.com/ojs/index.php/Revista Scientific/oai

Artículo Original / Original Article

\begin{tabular}{|c|c|c|}
\hline Mensaje sexual & Obsceno & 7 \\
\hline \multicolumn{3}{|l|}{ Imagen sexualizada } \\
\hline \multicolumn{3}{|l|}{ Ofensivo } \\
\hline \multicolumn{3}{|l|}{ Obsceno } \\
\hline Simpático & Identidad & 31 \\
\hline \multicolumn{3}{|l|}{ Me veo allí } \\
\hline \multicolumn{3}{|l|}{ Me identifico } \\
\hline \multicolumn{3}{|l|}{ Variedad } \\
\hline \multicolumn{3}{|l|}{ Vida } \\
\hline Tengo mi propia belleza & Libertad & 14 \\
\hline \multicolumn{3}{|l|}{ Libre } \\
\hline \multicolumn{3}{|l|}{ Diferencia } \\
\hline Extrañeza & Rechazo & 36 \\
\hline \multicolumn{3}{|l|}{ Rechazo } \\
\hline No me gusta & & \\
\hline
\end{tabular}

Fuente: La Autora (2020).

Por el contrario, en la tabla 4, en el grupo control aparecen sutilidades que apuntan a una identificación con alguna parte de la fotografía; es decir que a pesar de que la fotografía en su conjunto no les agrade, logran encontrar algún aspecto positivo en la imagen que ésta les devuelve. Pueden incluso identificarse con la situación recreada y hacerse presentes en ella.

\section{Conclusiones}

El rechazo radical del cuerpo, de lo femenino y de sus manifestaciones se sitúa como la principal problemática concernida en los TCA. La ausencia de un soporte simbólico que sostenga la propia imagen aparece en primer plano, y se traduce en la dificultad de investir el propio cuerpo con marcas de afecto o de valoración. Asimismo, lo que les viene del otro es una mirada extraña, que las deja sin referencias para construirse una identidad. Esta mirada, omnipresente y perturbadora, dictamina además cómo deben verse para ser consideradas amables. Esta instancia cruel que ubican fuera de sí 
mismas, las expone a sacrificios cada vez más inefables, que pueden llegar a la propia muerte.

La exposición al material fotográfico demuestra finalmente que el rol de la publicidad puede ser relativizado. No tiene un rol central ni se presenta como un factor desencadenante de la enfermedad. Se superpone eficazmente a las instancias psíquicas de censura y prohibición que, en el caso del sujeto anoréxico, se encuentran externalizadas. De este modo, la publicidad aparece como un martirio impuesto por la sociedad, aun cuando la instancia sádica que dictamina e impone se encuentra en realidad en el propio psiquismo del sujeto.

Es notable cómo las mujeres que no presentan estos trastornos pueden permanecer al abrigo de los ideales sociales, al inventar una forma individual de habitar el propio cuerpo. Muchas sortean las imposiciones sociales, y demuestran una y otra vez cómo éstas fracasan. Lo propio de lo femenino es, en efecto, lo que vuelve a una mujer enteramente diferente de otra.

Las mujeres anoréxicas no tienen una imagen propia, no saben cómo se ven exactamente, ni tampoco cómo quisieran verse, pero tampoco logran adoptar las imágenes preconfeccionadas que impone la publicidad. Solamente saben que no les gusta cómo son, ni cómo se ven y, a partir de esta certeza se entregan a una modificación radical de la imagen del cuerpo a través de los TCA.

El alcance de este estudio es, evidentemente, muy reducido y las conclusiones obtenidas no pueden ser generalizadas. No obstante, permite esclarecer la dinámica de los TCA y acercarnos cada vez más a la lógica que lleva a un sujeto femenino a ocupar una tal posición ante la propia existencia.

\section{Referencias}

Del-Río-Pérez, J., \& Medina-Aguerrebere, P. (2014). Análisis de la investigación sobre creatividad en publicidad en España de 1980 a 2012. El profesional de la información, 23(4), 401-408, e-ISSN: 1386- 
6710. Recuperado de: http://dx.doi.org/10.3145/epi.2014.jul.08

García-Ochoa, Y. (2010). El cuerpo femenino en la publicidad. Modelos publicitarios: entre la belleza real, la esbeltez o la anorexia. Revista Icono, 8(14), 223-243, e-ISSN: 1697-8293. Recuperado de: https://icono14.net/ojs/index.php/icono14/article/view/236

Lameiras, M., Calado, M., Rodríguez, Y., \& Fernández, M. (2003). Hábitos alimentarios e imagen corporal en estudiantes universitarios sin trastornos alimentarios. International Journal of Clinical and Health Psychology, 3(1), 23-33, e-ISSN: 1697-2600. Recuperado de: https://www.redalyc.org/articulo.oa?id=33730102

Maganto, C., \& Cruz, S. (2000). La imagen corporal y los trastornos alimenticios: Una cuestión de género. Cuadernos de Psiquiatría y Psicoterapia del Niño y del Adolescente, (30), 45-58, e-ISSN: 15755967. Recuperado de: http://www.sepypna.com/articulos/imagencorporal-trastornos-alimenticios/

Morales, A., Ramírez, W., Ureña, M., Sevilla, A., Umaña, P., \& Chavez, R. (2002). Anorexia y bulimia: caracterización y sistematización de la experiencia de intervención de una Clínica de Adolescentes. Acta Pediátrica Costarricense, 16(3), 93-108, ISSN: 1409-0090. Costa Rica: Asociación Costarricense de Pediatría.

Moreira, D. (2015). Diciéndose hombre o mujer: Una economía política del goce. Verba Volant. Revista de Filosofía y Psicoanálisis, 5(1), 24-34, eISSN: 2250-5776. Buenos Aires, Argentina: UCES - Editorial de la Universidad de Ciencias Empresariales y Sociales.

Murguía, S. (2013). Anorexia y Angustia. Nodvs, (40), 1-9, e-ISSN: 20138539. Barcelona, España: Sección Clínica de Barcelona - Instituto del Campo Freudiano.

Peláez, M., Raich, M., \& Labrador, F. (2010). Trastornos de la conducta alimentaria en España: Revisión de estudios epidemiológicos. 
OAI-PMH: http://www.indteca.com/ojs/index.php/Revista Scientific/oai

Artículo Original / Original Article

Revista mexicana de trastornos alimentarios, 1(1), 62-75, e-ISSN: 20071523. Recuperado de:

http://www.scielo.org.mx/scielo.php?script=sci arttext\&pid=S200715232010000100007

Pereña, F. (2007). Cuerpo y subjetividad: Acerca de la anorexia. Revista Española de Salud Pública, 81(5), 529-542, e-ISSN: 2173-9110. Recuperado de:

http://scielo.isciii.es/scielo.php?script=sci abstract\&pid=S1135$\underline{57272007000500009}$

Plaza, J. (2010). Medios de comunicación, anorexia y bulimia. La difusión mediática del 'anhelo de delgadez': un análisis con perspectiva de género. Revista Icono, 8(14), 62-83, e-ISSN: 1697-8293. Recuperado de: https://doi.org/10.7195/ri14.v8i3.229

Raich, R. (2004). Una perspectiva desde la psicología de la salud de la imagen corporal. Avances en Psicología Latinoamericana, 22, 15-27, e-ISSN: 2145-4515. Recuperado de:

https://revistas.urosario.edu.co/index.php/apl/article/view/1261

Rutsztein, G., Murawski, B., Elizathe, L., \& Scappatura, M. (2010). Trastornos alimentarios: Detección en adolescentes mujeres y varones de Buenos Aires. Un estudio de doble fase. Revista mexicana de trastornos alimentarios, 1(1), e-ISSN: 2007-1523. Recuperado de: http://www.scielo.org.mx/scielo.php?script=sci arttext\&pid=S200715232010000100006

Vaquero-Cristóbal, R., Alacid, F., Muyor, J., \& López-Miñarro, P. (2013). Imagen corporal; revisión bibliográfica. Nutrición Hospitalaria, 28(1). 27-35, e-ISSN: 0212-1611. Recuperado de:

http://scielo.isciii.es/scielo.php?script=sci abstract\&pid=S0212$\underline{16112013000100004}$ 
OAI-PMH: http://www.indteca.com/ojs/index.php/Revista Scientific/oai

Artículo Original / Original Article

\section{Claudia Gabriela Terán Ledesma}

e-mail: claudia.teran@uisek.edu.ec

Nacida en Quito, Ecuador, el 16 de noviembre del año

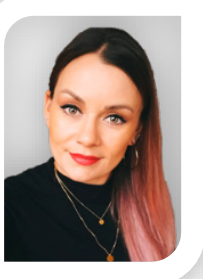
1987. Psicóloga clínica, graduada de la Universidad de las Américas (UDLA), ciudad de Quito, Ecuador; Máster en Psicología Clínica y Medicina Conductual por la Universidad Autónoma de Barcelona (UAB); mi investigación se enfoca en el análisis cualitativo de los trastornos alimentarios en mujeres; soy docente titular y Coordinadora de la Carrera de Psicología de la Universidad Internacional SEK (UISEK), Quito, Ecuador.

El contenido de este manuscrito se difunde bajo una Licencia de Creative Commons ReconocimientoNoComercial-Compartirlgual 4.0 Internacional 